\title{
Comparison of body mass index (BMI) with the CUN-BAE body adiposity estimator in the prediction of hypertension and type 2 diabetes
}

Vicente Martín ${ }^{1,2}$, Verónica Dávila-Batista ${ }^{1,12^{*}}$, Jesús Castilla ${ }^{2,3}$, Pere Godoy ${ }^{2,4}$, Miguel Delgado-Rodríguez ${ }^{2,5}$, Nuria Soldevila², Antonio J. Molina', Tania Fernandez-Villa', Jenaro Astray ${ }^{6}$, Ady Castro ${ }^{7}$, Fernando González-Candelas ${ }^{2,8}$, José María Mayoral ${ }^{9}$, José María Quintana ${ }^{2,10}$, Angela Domínguez ${ }^{2,11}$ and CIBERESP Cases and Controls in Pandemic Influenza Working Group, Spain

\begin{abstract}
Background: Obesity is a world-wide epidemic whose prevalence is underestimated by BMI measurements, but CUN-BAE (Clínica Universidad de Navarra - Body Adiposity Estimator) estimates the percentage of body fat (BF) while incorporating information on sex and age, thus giving a better match. Our aim is to compare the BMI and CUN-BAE in determining the population attributable fraction (AFp) for obesity as a cause of chronic diseases.
\end{abstract}

Methods: We calculated the Pearson correlation coefficient between BMI and CUN-BAE, the Kappa index and the internal validity of the BMI. The risks of arterial hypertension (AHT) and diabetes mellitus (DM) and the AFp for obesity were assessed using both the BMI and CUN-BAE.

Results: 3888 white subjects were investigated. The overall correlation between BMI and CUN-BAE was $R^{2}=0.48$, which improved when sex and age were taken into account $\left(R^{2}>0.90\right)$. The Kappa coefficient for diagnosis of obesity was low (28.7\%). The AFp was $50 \%$ higher for DM and double for AHT when CUN-BAE was used.

Conclusions: The overall correlation between BMI and CUN-BAE was not good. The AFp of obesity for AHT and $\mathrm{DM}$ may be underestimated if assessed using the BMI, as may the prevalence of obesity when estimated from the percentage of $\mathrm{BF}$.

Keywords: Obesity, Body mass index, Body fat, CUN-BAE, Population attributable fraction, Hypertension, Diabetes mellitus

\section{Background}

Obesity is seen as an emerging epidemic around the world because it represents a growing threat to the health of the population. It is a complex disease consisting of an excess or abnormal distribution or both of adipose tissue, giving rise to metabolic and endocrine alterations and changes in the immune system, resulting

\footnotetext{
*Correspondence: vdavb@unileon.es

${ }^{1}$ Grupo de Investigación Interacciones Gen-Ambiente y Salud - Universidad de León (Gigas), León, Spain

${ }^{12}$ Facultad de Ciencias de la Salud. Campus de Vegazana. Universidad de León, 24071 León, Spain

Full list of author information is available at the end of the article
}

in increased morbidity and mortality and a lower life expectation [1, 2]. Moreover, excess body fat (BF) is known to be associated with cardiovascular diseases and diabetes [3].

The body mass index (BMI) is the most frequently used measurement for diagnosing obesity, because of its simplicity and reliability. However, the BMI underestimates the prevalence of obesity by $50 \%$, in comparison with direct measurement techniques of adipose; its relationship with adiposity is influenced by age, sex and race $[1,4-7]$.

In this regard, an alternative for whites is the CUNBAE (Clínica Universidad de Navarra - Body Adiposity 
Estimator), which gives a closer correlation between adiposity and cardiovascular factors than BMI, improving our understanding of the impact of obesity levels on these chronic diseases [8].

Our aim is to compare the BMI and CUN-BAE and evaluation the population attributable fraction (AFp) for obesity as a cause of hypertension and type 2 diabetes.

\section{Methods}

\section{Population studied}

The present study incorporated all the white patients taking part in the cross-sectional project concerning the Risk Factors of Infuenza A(H1N1) in the 2009-10 and 2010-11 seasons aged over eighteen with a BMI $\geq$ $18.5 \mathrm{~kg} / \mathrm{m}^{2}$, with the exception of pregnant women. The project involved twenty-nine hospitals in seven Spanish autonomous regions and nine research groups in CIBERESP, the Spanish Consortium for Biomedical Research in Epidemiology and Public Health [9].

\section{Anthropometrical measurements}

The body mass index (BMI) was calculated in the standard way as $\mathrm{kg} / \mathrm{m}^{2}$. Patients were classified by BMI according to the criteria of the World Health Organization (WHO) and the Spanish Society for the Study of Obesity, with obesity being taken to be a BMI of $30 \mathrm{~kg} / \mathrm{m}^{2}$ or more for both sexes $[10,11]$.

The CUN-BAE figure was then calculated, using the following equation [8]:

$$
\begin{aligned}
\% B F= & -44.988+(0.503 \times \text { age })+(10.689 \times \text { sex }) \\
& +(3.172 \times B M I)-\left(0.026 \times B M I^{2}\right) \\
& +(0.181 \times B M I \times \text { sex })-(0.02 \times B M I \times \text { age }) \\
& -\left(0.005 \times B M I^{2} \times \text { sex }\right)+\left(0.00021 \times B M I^{2} \times \text { age }\right)
\end{aligned}
$$

where age was in years, and sex was coded as 0 for men and 1 for women. Obesity was taken to be a percentage of $\mathrm{BF} \geq 25 \%$ in males and $\geq 35 \%$ in women, increments of $5 \%$ being used to divide categories $[8,12,13]$.

Subjects were defined as hypertensive (AHT) or as having type 2 diabetes mellitus (DM) if they had previously been diagnosed for either.

\section{Statistical analyses}

Agreement between BMI and CUN-BAE was assessed by means of the Pearson correlation coefficient. The Kappa coefficient and its index of coincidence at $95 \%$ were calculated so as to classify patients as obese or not using both methods of determining obesity. All the analyses involved grouping by sex and into the two age bands of under 50 and 50 plus.

Association of type 2 diabetes mellitus (DM) or arterial hypertension (AHT) to BF was assessed using the two methods for calculating body fat. The comparative standard adopted was the normal weight category $[2,8]$, and the level of risk (crude odds ratio, cOR) was calculated for each of the distribution categories. By means of a logistic regression model adjusted odds ratio (aOR) figures were reckoned for the risk of AHT and DM by including in the model details of education, marital status and tobacco and alcohol use. Age was factored into the BMI analyses, but not into CUN-BAE, which already includes it. All these analyses were grouped by sex.

Calculation of the population attributable fraction (AFp) for AHT and DM in the BMI and CUN-BAE categories was on the basis of the following formula expressed as a percentage [14]:

$$
1-\sum_{l}^{k}(\mathrm{pd} / a O R)
$$

where pd is the proportion of those suffering from the ailments at the level of exposure, and aOR is the adjusted odds ratio.

Data analysis was performed with the Stata/SE 13 software package.

\section{Data confidentiality and ethical considerations}

All information collected was treated as confidential under the observational studies law. The study was approved by the Ethics Committee of the hospitals involved: Clinical Research Ethics Committee, Hospital Costa del Sol; Autonomous Clinical Trials Committee of Andalusia; Clinical Research Ethics Committee, Complejo Asistencial Universitario de León; Clinical Research Ethics Committee, Municipal Institute of Healthcare (CEICIMAS); Clinical Research Ethics Committee, Corporación Sanitaria ParcTaulí of Sabadell; Research Committee, Sant Joan de Déu University Hospital; Clinical Research Ethics Committee, Basque Country; Clinical Research Ethics Committee, Doctor Peset Univeristy Hospital, Valencia; and, Clinical Research Ethics Committee, Clinical Research Ethics Committee, General Directorate of Public Health, Valencia. Written informed consent was obtained from all patients.

\section{Results}

A total of 3888 patients were studied: 2033 men with an average age of 50.7 years, and 1855 women with an average age of 49.6 years. The average BMI was $26.9 \mathrm{~kg} / \mathrm{m}^{2}$ for the men and $26.3 \mathrm{~kg} / \mathrm{m}^{2}$ for the women. The average CUN-BAE was $27.1 \%$ of BF for the men and $37.6 \%$ for the women.

Figure 1 shows the distribution of BMI and CUNBAE. From the four groupings depending on sex and age. The correlation between BMI and CUN-BAE was low $\left(R^{2}=0.48\right)$, but increased considerably when sex was taken into account ( $R^{2}$ above 0.88 in both sexes). 


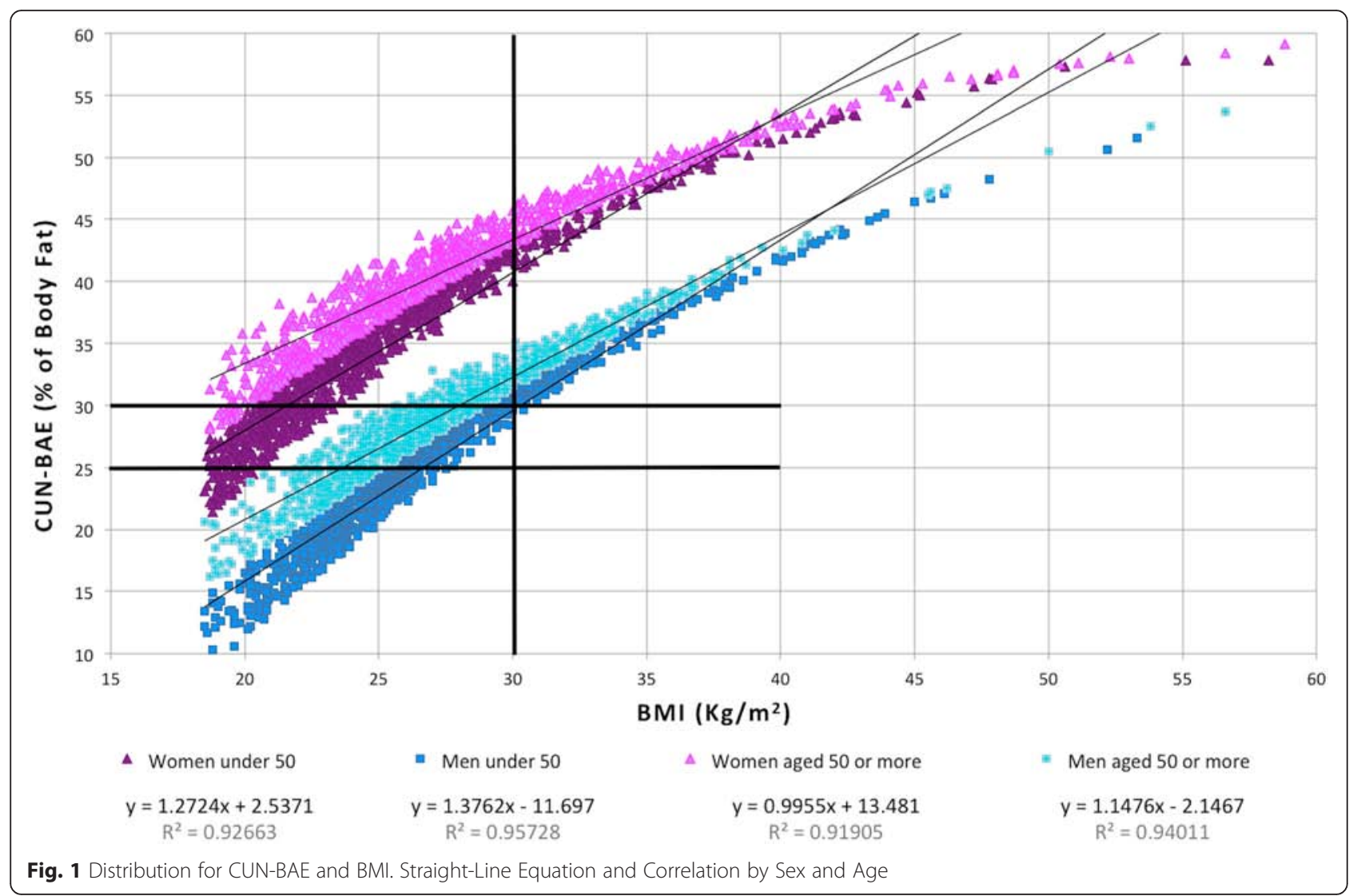

This improvement was even greater when age (under 50 or 50 plus) was also considered, when $R^{2}$ was greater than 0.92 (Table 1).

The degree of agreement measured by the Kappa coefficient for diagnosis of obesity was low $(28.7 \%)$, similar for both sexes and somewhat better for those under 50 than the others. This low level of agreement with BMI explains the different prevalence of obesity noted in accordance with the criterion used. In all cases the prevalence of obesity as based on the estimation of body fat CUN-BAE is three times higher than the BMI would suggest.

Table 2 and Fig. 2 show that as the figures for both $\mathrm{BMI}$ and CUN-BAE increased, so did the prevalence of $\mathrm{AHT}$ and the aOR values. However, this gradient was more evident with CUN-BAE than with BMI, basically owing to a lesser prevalence of AHT in the normal weight group based on the criterion of estimated body

Table 1 Correlation and degree of agreement between CUN-BAE and BMI and prevalence of obesity according to sex and age groups

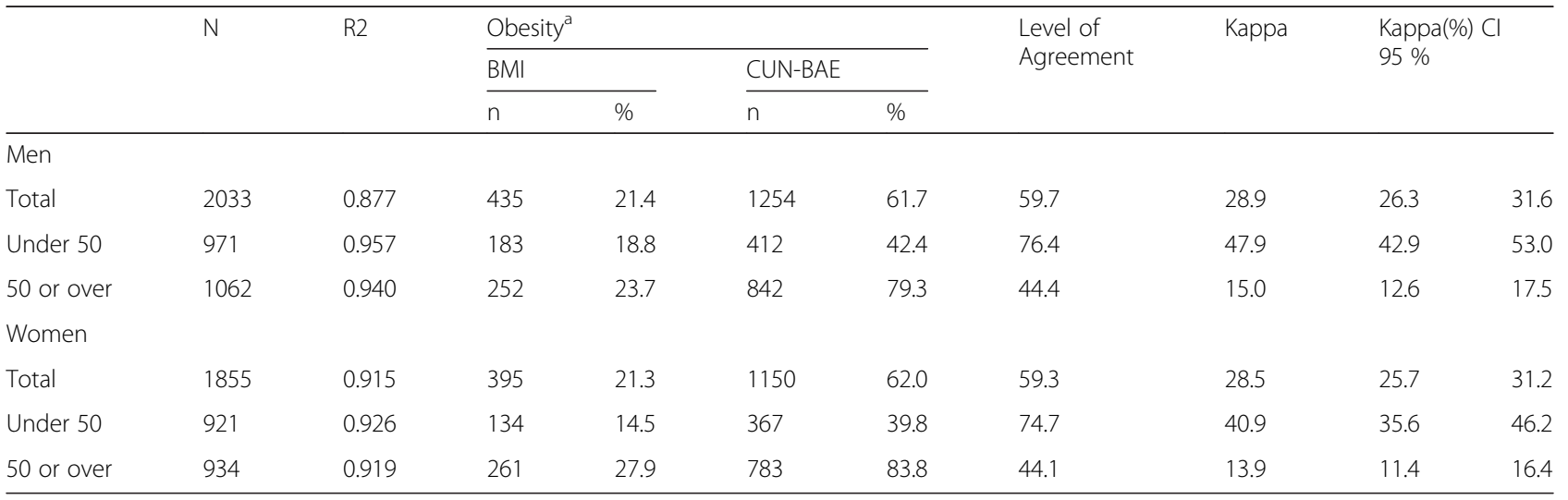

abesity: $\mathrm{BMI} \geq 30 \mathrm{~kg} / \mathrm{m} 2$, CUN-BAE $\geq 25 \%$ body fat in men and $25 \%$ in women 
Table 2 Distribution of prevalence and risk of hypertension by sex according to BMI and CUN-BAE

\begin{tabular}{|c|c|c|c|c|c|c|c|c|}
\hline & $N$ & $n$ & Prev & $\mathrm{COR}$ & Cl $95 \%$ & $a O R^{a}$ & Cl $95 \%$ & AFp(\%) \\
\hline \multicolumn{9}{|l|}{ Men } \\
\hline \multicolumn{9}{|c|}{ BMI (kg/m2) } \\
\hline $18.5-24.9$ & 749 & 152 & 20.29 & 1 & & 1 & & \multirow[t]{5}{*}{37.00} \\
\hline $25-29.9$ & 849 & 254 & 29.92 & 1.68 & $1.33-2.11$ & 1.33 & $1.02-1.74$ & \\
\hline 30-34.9 & 328 & 169 & 51.52 & 4.17 & $3.15-5.53$ & 3.93 & $2.84-5.44$ & \\
\hline $35-39.9$ & 74 & 37 & 50.00 & 3.93 & $2.40-6.40$ & 4.50 & $2.56-7.89$ & \\
\hline$\geq 40$ & 33 & 16 & 48.48 & 3.70 & $1.83-7.49$ & 8.66 & $3.80-19.39$ & \\
\hline \multicolumn{9}{|c|}{ CUN-BAE (\%BF) } \\
\hline$\leq 19.9$ & 258 & 21 & 8.14 & 1 & & 1 & & \multirow[t]{5}{*}{74.03} \\
\hline $20-24.9$ & 521 & 79 & 15.16 & 2.02 & $1.22-3.35$ & 1.67 & $1.00-2.80$ & \\
\hline $25-29.9$ & 631 & 208 & 32.96 & 5.55 & $3.45-8.93$ & 3.80 & $2.32-6.21$ & \\
\hline 30-34.9 & 415 & 199 & 47.95 & 10.40 & $6.40-16.90$ & 6.80 & $4.11-11.25$ & \\
\hline$\geq 35$ & 208 & 121 & 58.17 & 15.70 & $9.29-26.52$ & 11.24 & $6.54-19.31$ & \\
\hline \multicolumn{9}{|l|}{ Women } \\
\hline \multicolumn{9}{|c|}{ BMI (kg/m2) } \\
\hline $18.5-24.9$ & 895 & 119 & 13.30 & 1 & & 1 & & \multirow[t]{5}{*}{45.32} \\
\hline $25-29.9$ & 565 & 180 & 31.86 & 3.05 & $2.35-3.96$ & 1.99 & $1.46-2.71$ & \\
\hline $30-34,9$ & 259 & 110 & 42.47 & 4.81 & $3.52-6.58$ & 2.73 & $1.87-3.98$ & \\
\hline $35-39.9$ & 86 & 45 & 52.33 & 7.15 & $4.50-11.39$ & 4.93 & $2.83-8.58$ & \\
\hline$\geq 40$ & 50 & 26 & 52.00 & 7.06 & $3.93-12.71$ & 7.71 & $3.80-15.64$ & \\
\hline \multicolumn{9}{|c|}{ CUN-BAE (\%BF) } \\
\hline$\leq 29.9$ & 303 & 9 & 2.97 & 1 & & 1 & & \multirow[t]{5}{*}{89.14} \\
\hline 30-34.9 & 402 & 36 & 8.96 & 3.21 & $1.52-6.78$ & 2.97 & $1.34-6.57$ & \\
\hline $35-39.9$ & 464 & 108 & 23.28 & 9.91 & 4.93-19.90 & 7.82 & $3.71-16.49$ & \\
\hline $40-44.9$ & 389 & 165 & 42.42 & 24.06 & $12.03-48.12$ & 16.10 & 7.63-33.99 & \\
\hline$\geq 45$ & 297 & 162 & 54.55 & 39.20 & 19.44-79.06 & 23.30 & $10.93-49.69$ & \\
\hline
\end{tabular}

aOR: BMI (age, educational level, marital status, tobacco and alcohol use); CUN-BAE (educational level, marital status, tobacco and alcohol use) Abbreviations: $C l$ confidence interval, $a O R$ adjusted odds ratio, AFp population attributable fraction, BMI body mass index, CUN-BAE Clínica Universidad de Navarra - Body Adiposity Estimator, BF body fat
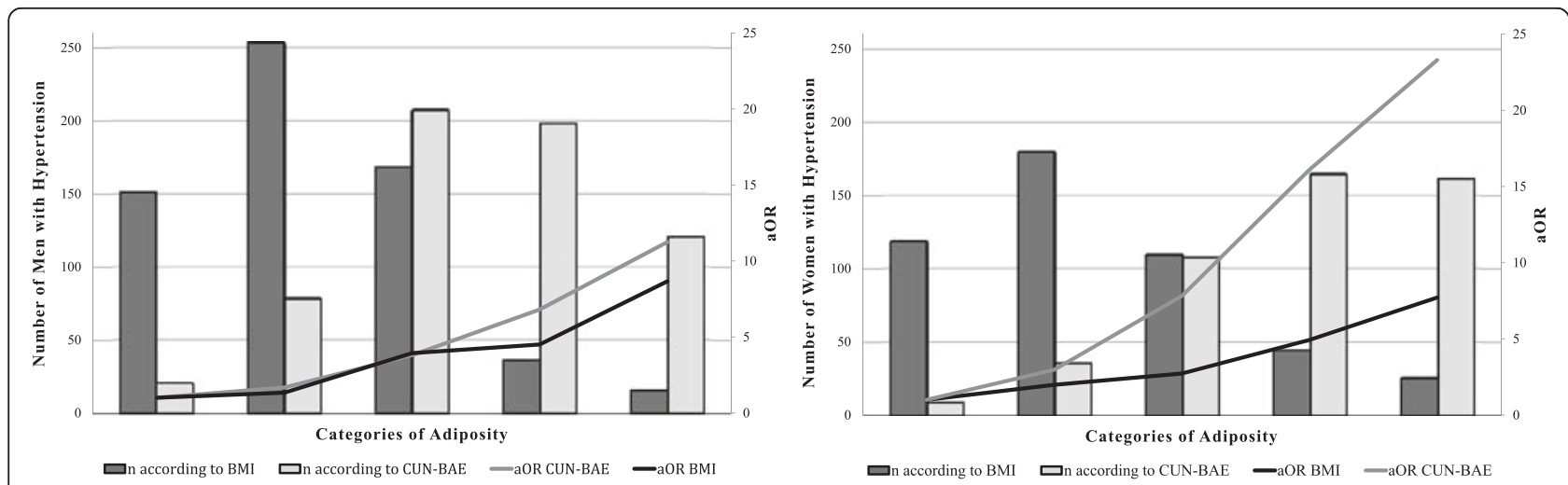

Fig. 2 Distribution of Number of Cases of hypertension and aOR, by sex. Legends: Categories of Adiposity: With BMI (C1: 18,5-24.9, C2: 25-29.9, C3: 30-34,9, C4: 35-39.9, C5: $\geq 40 \mathrm{~kg} / \mathrm{m} 2)$ with CUN-BAE men (C1: $\leq 19.9$, C2: 20-24.9, C3: 25-29.9, C4: 30-34.9, C5: $\geq 35$ \%BF) and women (C1: $\leq 29.9$, C2: 30-34.9, C3: 35-39.9, C4: 40-44.9, C5: $\geq 45 \%$ BF) 
fat $(8.1 \%$ and $3.0 \%$ in men and women respectively) than when based on BMI $(20.3 \%$ and $13.3 \%$ in men and women respectively). The AFp of AHT assigned to the two methods of assessing adiposity was found to be double for both men and women for CUN-BAE in comparison with BMI $(37.0 \%$ and $45.4 \%$ with BMI; $74.0 \%$ and $89.1 \%$ with CUN-BAE for men and women, respectively). In men this difference is due to the differing distributions of cases with the two methods of evaluating adiposity, and a mixture of this and differences in risks in the case of women.

Table 3 and Fig. 3 show how prevalence and aOR figures for DM increase according to the category of obesity in both sexes for CUN-BAE and in women for BMI. This gradient is more obvious with CUN-BAE than with BMI for men and similar for the two among women, although they yield different distributions. Regarding the AFp of DM the CUN-BAE almost tripled the attributable percentage in comparison with BMI in men $(71.54 \%$ as opposed to $26.19 \%)$, while for women the figure was $50 \%$ higher $(65.19 \%$ as opposed to $40.38 \%)$.

\section{Discussion}

The correlation found between BMI and CUN-BAE in overall analyses was not good $\left(R^{2}=0.48\right)$. This coincides with the findings of Romero-Corral et al. and Sardinhha et al., who also noted a low overall agreement $\left(R^{2}\right.$ of 0.40 to 0.47 ) between $\mathrm{BMI}$ and the percentage of $\mathrm{BF}$ assessed by bio-electric impedance [7, 15]. This poor correlation is explained by the fact that adiposity is dependent upon sex and age. It is well known that with the same BMI women and more elderly subjects have a greater percentage of BF [15-18]. This same fact also explains the improvement in correlation when sex, age, or both are factored into the figures. This was also

Table 3 Distribution of prevalence and risk of diabetes II by sex according to BMI and CUN-BAE, 2009-2011

\begin{tabular}{|c|c|c|c|c|c|c|c|c|}
\hline & $\mathrm{N}$ & $n$ & Prev & $\mathrm{COR}$ & Cl $95 \%$ & $\mathrm{aOR}^{\mathrm{a}}$ & $\mathrm{Cl} 95 \%$ & AFp(\%) \\
\hline \multicolumn{9}{|l|}{ MEN } \\
\hline \multicolumn{9}{|l|}{ IMC } \\
\hline $18.5-24.9$ & 749 & 73 & 9.75 & 1 & & 1 & & \multirow[t]{5}{*}{26.19} \\
\hline $25-29.9$ & 849 & 113 & 13.31 & 1.42 & $1.04-1.94$ & 1.13 & $0.80-1.58$ & \\
\hline $30-34,9$ & 328 & 79 & 24.09 & 2.94 & $2.07-4.17$ & 2.37 & $1.62-3.48$ & \\
\hline $35-39.9$ & 74 & 21 & 28.38 & 2.97 & $1.80-4.92$ & 3.19 & $1.83-5.55$ & \\
\hline$\geq 40$ & 33 & 5 & 15.15 & & & & & \\
\hline \multicolumn{9}{|l|}{ CUN-BAE } \\
\hline$\leq 19.9$ & 258 & 9 & 3.49 & 1 & & 1 & & \multirow[t]{5}{*}{71.54} \\
\hline $20-24.9$ & 521 & 35 & 6.72 & 1.99 & $0.94-4.21$ & 1.66 & $0.78-3.55$ & \\
\hline $25-29.9$ & 631 & 95 & 15.06 & 4.90 & $2.44-9.87$ & 3.49 & $1.70-7.16$ & \\
\hline 30-34.9 & 415 & 87 & 20.96 & 7.34 & $3.62-14.86$ & 4.91 & $2.37-10.14$ & \\
\hline$\geq 35$ & 208 & 65 & 31.25 & 12.58 & $6.08-26.01$ & 8.34 & $3.96-17.56$ & \\
\hline \multicolumn{9}{|l|}{ WOMEN } \\
\hline \multicolumn{9}{|l|}{ IMC } \\
\hline $18.5-24.9$ & 895 & 50 & 5.59 & 1 & & 1 & & \multirow[t]{5}{*}{40.38} \\
\hline 25-29.9 & 565 & 76 & 13.45 & 2.63 & $1.81-3.82$ & 1.78 & $1.20-2.64$ & \\
\hline $30-34,9$ & 259 & 45 & 17.37 & 3.55 & $2.31-5.46$ & 2.09 & $1.33-3.31$ & \\
\hline 35-39.9 & 86 & 21 & 24.42 & 5.46 & $3.09-9.64$ & 3.44 & $1.86-6.35$ & \\
\hline$\geq 40$ & 50 & 19 & 38,0 & 10.36 & $5.47-19.61$ & 8.13 & $4.08-16.18$ & \\
\hline \multicolumn{9}{|l|}{ CUN-BAE } \\
\hline$\leq 29.9$ & 303 & 10 & 3.3 & 1 & & 1 & & \multirow[t]{5}{*}{65.19} \\
\hline 30-34.9 & 402 & 23 & 5.72 & 1.78 & $0.83-3.79$ & 1.64 & $0.76-3.54$ & \\
\hline $35-39.9$ & 464 & 36 & 7.76 & 2.46 & $1.20-5.04$ & 1.86 & $0.89-3.87$ & \\
\hline $40-44.9$ & 389 & 61 & 15.68 & 5.45 & $2.74-10.83$ & 3.47 & $1.69-7.13$ & \\
\hline$\geq 45$ & 297 & 81 & 27.27 & 10.99 & $5.57-21.69$ & 6.49 & $3.16-13.3$ & \\
\hline
\end{tabular}

aOR: BMI (age, educational level, marital status, tobacco and alcohol use); CUN-BAE (educational level, marital status, tobacco and alcohol use) Abbreviations: $C l$ confidence interval, aOR adjusted odds ratio, AFp population attributable fraction, BMI body mass index, CUN-BAE Clínica Universidad de Navarra - Body Adiposity Estimator, BF body fat 

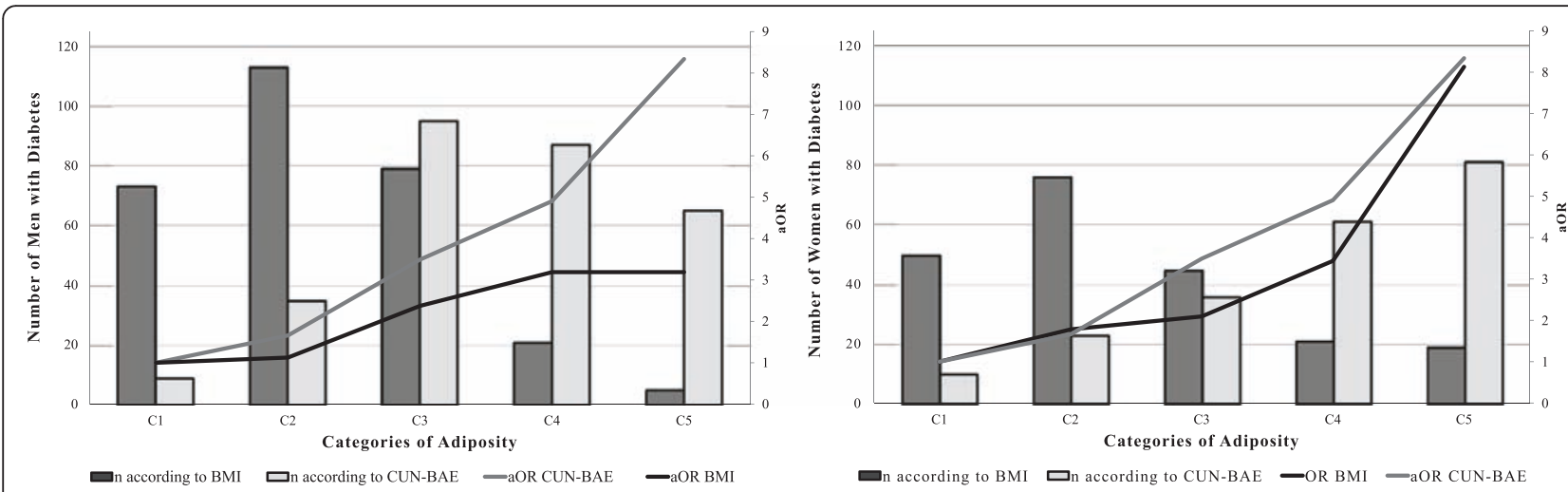

Fig. 3 Distribution of the Number of Cases of Diabetes and aOR, by sex. Legends: Categories of Adiposity: With BMI (C1: 18,5-24.9, C2: 25-29.9, C3: 30-34,9, C4: 35-39.9, C5: $\geq 40$ Kg/m2) with CUN-BAE men (C1: $\leq 19.9$, C2: 20-24.9, C3: 25-29.9, C4: 30-34.9, C5: $\geq 35$ \%BF) and women (C1: $\leq$ 29.9, C2: 30-34.9, C3: 35-39.9, C4: 40-44.9, C5: $\geq 45$ \%BF)

observed by Gallagher et al., who found an overall correlation $R^{2}=0.26$, but when sex and age were taken into account the correlation was much better, with values for $\mathrm{R}^{2}$ of up to 0.67 [18]. On this point, it should be noted that there was a good coincidence between the correlation figures obtained in studies comparing BMI with directly measured body fat and body fat estimated with CUN-BAE [8, 18-20].

Regarding the classification of obesity, this study opted for $\mathrm{BMI} \geq 30 \mathrm{~kg} / \mathrm{m}^{2}$, regardless of sex or age, since this is the criterion recommended by the WHO, the most extensively used world-wide and by scientific associations in Spain $[2,11]$. The cut-off point for CUN-BAE was based on the criteria indicated by the authors who described the formula for calculating it, and was thus coincident with recommendations in other studies [12, 21]. On the basis of these norms, there is a low level of agreement in classification of obesity between BMI and the percentage of BF estimated by CUN-BAE, with a Kappa coefficient of $28.7 \%$. In other publications the Kappa between BMI and percentage of BF was similarly low in women (between $15 \%$ and $30 \%$ ), while in men greater variations were noted (between $8 \%$ and $70 \%$ ).

In addition to BMI as compared to the percentage of $\mathrm{BF}$, prevalence of obesity estimated with CUN-BAE $(61.8 \%)$ was much higher than with BMI $(21.35 \%)$. This coincided with other publications in which the prevalences of obesity estimated through the percentage of $\mathrm{BF}$ were almost double those yielded by BMI $[4,22]$ or even up to six times higher [23].

Diabetes and AHT are common ailments clearly related to obesity as a risk factor, which is why we studied their association with the two ways of assessing body fat, to find that estimates of $\mathrm{BF}$ according to CUN-BAE were more clearly related to AHT and DM than results from BMI, just as was noted by Dervaux et al. in the assessment of body fat percentages [24]. The main reason for this clearer association lies in the lower prevalence of AHT and DM in the normal weight grouping as assigned on the criterion of estimated body fat than as assigned by BMI. Furthermore, the greater number of instances of AHT and DM are to be found in lower-weight categories according to BMI, while with CUN-BAE they are present in a smaller number of individuals. Other studies have also shown a better correlation of CUN-BAE with other biological markers of cardiovascular and metabolic diseases $[8,25]$.

The final result, the disparity in aOR and essentially in the distribution of patients according to BMI or CUN$\mathrm{BAE}$, comes down to the great differences observed in the attributable portion of the population for AHT or $\mathrm{DM}$ on the basis of quantity of body fat. Indeed, the fact that the majority of patients had high percentage of BF, while with BMI they were assigned to lower categories, goes a long way towards explaining the total number of cases attributed to higher than normal weight. In almost all instances the classification of patients according to CUN-BAE almost doubled the AFp relative to classification in accordance with BMI. It may also be of some relevance that the reference group with BMI (normal weight) is a very broad grouping in which risk may be expected not to be homogeneous, in the sense that individuals in the upper part of the range might present a risk more like that of the over-weight than that of the lower part of the normal weight spectrum. All of this may cast a doubt upon estimates made of portions or fractions of the population and cases of AHT and DM attributable to obesity as a function of BMI $[26,27]$, so that the real impact of obesity in these pathologies may be much greater than assumed.

CUN-BAE has been proposed as a substitute for the BMI. Few studies have assessed its usefulness for classifying obesity or determining obesity-related cardiovascular risks. Nevertheless such studies as have been carried 
out report the same phenomenon as we do here, showing that CUN-BAE classes a greater number of subjects as obese and therefore greatly reduces the number of individuals in the reference category [28-30].

One possible limitation is that the highest adiposity category in men was established to avoid a sample size problem. Furhtermore, in our findings the sample may not have been representative of the population as a whole: the subjects were patients admitted to hospital or making use of health services for various reasons, so the prevalence of obesity and of AHT and DM was higher than in the population in general $[31,32]$. However, the aOR observed in relation to BMI for AHT and DM was very similar to that reported in another study [26].

\section{Conclusions}

Although the overall correlation between BMI and the BF estimator was not good, it improved when sex and age were taken into account.

There is a low level of agreement in accordance with the criterion used. The prevalence of obesity as based on estimation of body fat is the three times higher than the BMI would suggest, which could lead to an underestimation of the prevalence of obesity.

CUN-BAE showed links with hypertension and diabetes mellitus, and presented a better gradient than BMI did. The AFp for AHT was double when assessed with CUN-BAE as compared to BMI, while for DM it was more than $50 \%$ higher. This brings into question the reliability of calculations undertaken to assess the impact of obesity on thesepathologies.

\section{Abbreviations}

AFp: population attributable fraction; AHT: arterial hypertension; BF: body fat; BMI: body mass index; CUN-BAE: Clínica Universidad de Navarra - Body adiposity estimator; DM: diabetes mellitus; WHO: World Health Organization.

\section{Competing interest}

The authors declare that they have no competing interests

\section{Authors' contributions}

VM directed the study; VM and VDB analysed the data and wrote the manuscript, AD JC PG NS MDR AJM TFV JA AC FGC JMM JMQ and the CIBERESP Working Group conceived, performed and designed the study; and AD JC PG NS MDR AJM TFV JA AC FGC JMM JMQ contributed to the supervision of the study and critical analysis of the article. All authors read and approved the final manuscript.

\section{Acknowledgements}

We thank the physicians of the Sentinel Network of the participating Spanish regions and the study interviewers for their help and collaboration. Funding: This study was supported by the Ministry of Science and Innovation, Carlos III Institute of Health, Programme of Research on Influenza A/H1N1 (Grant GR09/0030), and the Catalan Agency for the Management of Grants for University Research (AGAUR Grant number 2009/ SGR 42). Verónica Dávila-Batista: Predoctoral contract financed by the Ministry of Education of the Junta de Castilla y Leon and the European Social Fund. The other members of the CIBERESP Cases and Controls in Pandemic Influenza Working Group are: Andalusia: Ernestina Azor, Jerónimo Carrillo, Rosa Moyano, Juan Antonio Navarro, Manuel Vázquez, Francisco Zafra (Médico Centinela); Ma Fe Bautista Martín, Jose Ma Navarro, Irene Pedrosa
Corral, Mercedes Pérez Ruiz (Laboratorio de Referencia de Gripe); Virtudes Gallardo, Esteban Pérez (Servicio de Epidemiología), José Ramón Maldonado (Hospital de Torrecárdenas), Aurea Morillo (Hospital Virgen del Rocío), Ma Carmen Ubago (Hospital Virgen de las Nieves). Castile and Leon: Demetrio Carriedo, Florentino Díez, Isabel Fernández-Natal, Silvia Fernández (Compl. Asist. Universitario, León); Javier Castrodeza, Carolina Rodríguez, Sonia Tamames (Consejería de Sanidad de la Junta de Castilla y León); Pilar Sanz (Universidad de León); Raul Ortiz de Lejarazu (Centro Nacional de Gripe de la Universidad de Valladolid); Alberto Pérez (Servicio de Vigilancia

Epidemiológica); Pedro Redondo (Servicio Territorial de Sanidad y Bienestar Social); Ana Pueyo, José Luis Viejo (Complejo Asistencial de Burgos).

Catalonia: Jordi Alonso (IMIM-Hospital del Mar); Ferrán Barbé (Hospital Arnau de Vilanova); Lluis Blanch, Gemma Navarro (Hospital de Sabadell); Xavier Bonfill, Joaquin López-Contreras, Virginia Pomar, María Teresa Puig (Hospital de Sant Pau); Eva Borràs, Ana Martínez, Núria Torner (Dirección General de Salud Pública); Francesc Calafell (Universitat Pompeu Fabra); Joan Cayla, Cecilia Tortajada (Agencia de Salud Publica de Barcelona); I Garcia, Juan Ruiz (Hospital Germans Trias i Pujol); Juan Jose Garcia (Hospital Sant Joan de Deu); Joaquim Gea, Juan Pablo Horcajada (Universitat Pompeu Fabra_CIBER Enfermedades Respiratorias); Ned Hayes (Hospital Clínic_CRESIB); Fernando Moraga (Hospital Vall d'Hebrón); Tomas Pumarola (Laboratorio de Referencia de Gripe); Jordi Dorca (Hospital de Bellvitge); Marc Sáez (Universidad de Girona); A Agustí, Antoni Trilla, Ana Vilella (Hospital Clínic de Barcelona), Maretva Baricot, Olatz Garín (CIBERESP). Madrid Community: Ricard Génova, Margarita García Barquero, Elisa Gil, Susana Jiménez, Fernando Martín, María Luisa Martínez, Silvia Sánchez (Subdirección de Promoción de la Salud y Prevención); Rafael Cantón, Ana Robustillo (Hospital Ramón y Cajal); Carlos Álvarez, Ana Hernandez Voth, Francisco Pozo (Hospital 12 de octubre), José Ramón Paño (Hospital La Paz). Navarre: Antonia Martínez, Leyre Martínez (Inst. de Salud Pública), María Ruiz, Patricia Fanlo, Francisco Gil, Victor Martínez-Artola (Compl. Hosp. Navarra), María Eugenia Ursua, Maite Sota, María Teresa Virto, Juana Gamboa, Felipe Pérez-Afonso (Médico Centinelas). The Basque Country: Urko Aguirre, Alberto Caspelastegui, Pedro Pablo España, Susana García (Hospital Galdakao); Javier Arístegui, Amaia Bilbao, Antonio Escobar (Hospital Basurto); Itziar Astigarraga, José María Antoñana (Hospital de Cruces); Gustavo Cilla, Javier Korta, Emilio Pérez Trallero (Hospital Donostia), José Luis Lobo (Hospital Txagorritxu), Francisco J. Troya (Hospital de Santiago). Valencia Community: María Morales (Hospital General Universitario).

We would also like to acknowledge Dr Javier Llorca, Javier Gómez-Ambrosi and Dr Gema Frühbeck, for their comments and help.

\section{Author details}

${ }^{1}$ Grupo de Investigación Interacciones Gen-Ambiente y Salud - Universidad de León (Gigas), León, Spain. ${ }^{2}$ CIBER Epidemiología y Salud Pública, Madrid, Spain. ${ }^{3}$ Instituto de Salud Pública de Navarra, Pamplona, Spain. ${ }^{4}$ Departament de Salut, Generalitat de Catalunya, Barcelona, Spain. ${ }^{5}$ División de Medicina Preventiva y Salud Pública, Universidad de Jaén, Jaén, Spain. ${ }^{6}$ Subdirección de Vigilancia. Comunidad de Madrid, Madrid, Spain. ${ }^{7}$ CIBER Enfermedades Respiratorias, Madrid, Spain. ${ }^{8}$ Unidad Mixta Genómica y Salud CSISP (FISABIO)-Universitat de València, Valencia, Spain. ${ }^{9}$ Servicio de Vigilancia de Andalucía, Sevilla, Spain. ${ }^{10}$ Fundación Vasca de Innovación e Investigación Sanitarias, Sondika, Spain. ${ }^{11}$ Departament de Salut Pública, Universitat de Barcelona, Barcelona, Spain. ${ }^{12}$ Facultad de Ciencias de la Salud. Campus de Vegazana. Universidad de León, 24071 León, Spain.

Received: 28 April 2015 Accepted: 13 January 2016

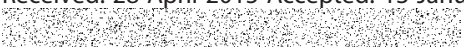

References

1. Haslam D, James W. Obesity. Lancet. 2005;366(9492):1197-209.

2. World Health Organization (WHO). Obesity and overweight. Fact sheet $\mathrm{N}^{\circ}$ 311. 2013. http://www.who.int/mediacentre/factsheets/fs311/en/. Accessed May 21, 2014

3. Bastien $\mathrm{M}$, Poirier P, Lemieux I, Després J. Overview of epidemiology and contribution of obesity to cardiovascular disease. Prog Cardiovasc Dis. 2014; 56(4):369-81.

4. Okorodudu D, Jumean M, Montori V, Romero-Corral A, Somers V, Erwin P, et al. Diagnostic performance of body mass index to identify obesity as defined by body adiposity: a systematic review and meta-analysis. Int J Obes. 2010;34(5):791-9. 
5. Centers for Disease Control and Prevention (CDC). About BMI for Adults. 2015. http://www.cdc.gov/healthyweight/assessing/bmi/adult_bmi/index. html. Accessed March 10, 2015.

6. Prentice AM, Jebb SA. Beyond body mass index. Obes Rev. 2001;2(3): 141-7.

7. Romero-Corral A, Somers V, Sierra-Johnson J, Thomas R, Collazo-Clavell M, Korinek J, et al. Accuracy of body mass index in diagnosing obesity in the adult general population. Int J Obes. 2008;32(6):959-66.

8. Gómez-Ambrosi J, Silva C, Catalán V, Rodríguez A, Galofré J, Escalada J, et al. Clinical usefulness of a new equation for estimating body fat. Diabetes Care. 2012;5(2):383.

9. Domínguez A, Alonso J, Astray J, Baricot M, Cantón R, Castilla J, et al. Factores de riesgo de hospitalización por gripe (H1N1) 2009 y efectividad de intervenciones farmacológicas y no farmacológicas en su prevención. Estudio de casos y controles. Rev Esp Salud Publica. 2011:85(1):3-15.

10. World Health Organization. Obesity: preventing and managing the global epidemic. Report of a WHO consultation. Report of a WHO Consultation. Geneva: Technical Report Series, No. 894; 2000

11. Salas-Salvadó J, Rubio M, Barbany M, Moreno B, Grupo colaborativo de la SEEDO. SEEDO 2007 Consensus for the evaluation of overweight and obesity and the establishment of therapeutic intervention criteria. Med Clin (Barc). 2007;128(5):184-96.

12. Romero-Corral A, Lopez-Jimenez F, Sierra-Johnson J, Somers VK Differentiating between body fat and lean mass-how should we measure obesity? Nat Clin Pract Endocrinol Metab. 2008;4(6):322-3.

13. De Lorenzo A, Deurenberg P, Pietrantuono M, Di Daniele N, Cervelli V, Andreoli A. How fat is obese? Acta Diabetol. 2003;40 Suppl 1:\$254-7.

14. Llorca J, Fariñas-Alvarez C, Delgado-Rodríguez M. Fracción atribuible poblacional: cálculo e interpretación. Gac Sanit. 2001;15(1):61-7.

15. Sardinha L, Lohman T, Teixeira P, Guedes D, Going S. Comparison of air displacement plethysmography with dual-energy X-ray absorptiometry and 3 field methods for estimating body composition in middle-aged men. Am J Clin Nutr. 1998;68(4):786-93.

16. Shah N, Braverman E. Measuring adiposity in patients: the utility of body mass index (BMI), percent body fat, and leptin. PLoS ONE. 2012;7(4):e33308.

17. Vasconcelos F, Cordeiro B, Rech C, Petroski E. Sensitivity and specificity of the body mass index for the diagnosis of overweight/obesity in elderly. Cad Saude Publica. 2010;26(8):1519-27.

18. Gallagher D, Visser M, Sepúlveda D, Pierson R, Harris T, Heymsfield S. How useful is body mass index for comparison of body fatness across age, sex, and ethnic groups? Am J Epidemiol. 1996;143:228-39.

19. Jackson A, Stanforth P, Gagnon J, Rankinen T, Leon A, Rao D, et al. The effect of sex, age and race on estimating percentage body fat from body mass index: The Heritage Family Study. Int J Obes. 2001;26(6):789-96.

20. Heydari S, Ayatollahi S, Zare N. Diagnostic value of bioelectrical impedance analysis versus body mass index for detection of obesity among students. Asian J Sports Med. 2011;2(2):68-74.

21. Grundy S. Obesity, metabolic syndrome, and cardiovascular disease. J Clin Endocrinol Metab. 2004;89(6):2595-600.

22. Pongchaiyakul C, Nguyen T, Kosulwat V, Rojroongwasinkul N, Charoenkiatkul S, Pongchaiyakul C. Defining obesity by body mass index in the Thai population: an epidemiologic study. Asia Pac J Clin Nutr. 2006;15(3):293-9.

23. Rodríguez-Rodríguez E, López-Plaza B, López-Sobaler A, Ortega R. Prevalencia de sobrepeso y obesidad en adultos españoles. Nutr Hosp. 2011:26(2):355-63.

24. Dervaux N, Wubuli M, Megnien J, Chironi G, Simon A. Comparative associations of adiposity measures with cardiometabolic risk burden in asymptomatic subjects. Atherosclerosis. 2008;201(2):413-7.

25. Haghighatdoost F, Sarrafzadegan N, Mohammadifard N, Asgari S, Boshtam $M$, et al. Assessing body shape index (ABSI) as a predictor for the risk of cardiovascular diseases and metabolic syndrome among Iranian adults. Nutrition. 2014;30(6):636-44.

26. Jiang Y, Chen $Y$, Manuel D, Morrison H, Mao Y. Obesity Working Group. Quantifying the impact of obesity category on major chronic diseases in Canada. Sci World J. 2007;7:1211-21.

27. Wilson P, D'Agostino R, Sullivan L, Parise H, Kannel W. Overweight and obesity as determinants of cardiovascular risk: the Framingham experience. Arch Intern Med. 2002;162(16):1867-72.

28. Gómez-Ambrosi J, Silva C, Galofré J, Escalada J, Santos S, Millán D, et al. Body mass index classification misses subjects with increased cardiometabolic risk factors related to elevated adiposity. Int J Obes. 2012 36(2):286-94.

29. Zubiaga Toro L, Ruiz-Tovar Polo J, Díez-Tabernilla M, Giner Bernal L, Arroyo Sebastián A, Calpena RR. CUN-BAE formula and biochemical factors as predictive markers of obesity and cardiovascular disease in patients before and after sleeve gastrectomy. Nutr Hosp. 2014;30(2):281-6.

30. Fuster-Parra P, Bennasar-Veny M, Tauler P, Yañez A, López-González A, Aguiló A. A comparison between multiple regression models and CUN-BAE equation to predict body fat in adults. PLoS ONE. 2015;10(3):e0122291.

31. Instituto Nacional de Estadistica. Encuesta Nacional de Salud 2011 - 2012. Nota de Prensa. Ministerio de Sanidad, Servicios Sociales e lgualdad; 2013. Available from: http://www.ine.es/prensa/np770.pdf

32. Van Kerkhove M, Vandemaele K, Shinde V, Jaramillo-Gutierrez G, Koukounari A, Donnelly C, et al. Risk factors for severe outcomes following 2009 influenza A (H1N1) infection: a global pooled analysis. PLoS Med. 2011;8(7): e1001053.

\section{Submit your next manuscript to BioMed Central and we will help you at every step:}

- We accept pre-submission inquiries

- Our selector tool helps you to find the most relevant journal

- We provide round the clock customer support

- Convenient online submission

- Thorough peer review

- Inclusion in PubMed and all major indexing services

- Maximum visibility for your research

Submit your manuscript at www.biomedcentral.com/submit
C) Biomed Central 